\section{NEEDS OF LOW-INCOME FAMILIES*}

A SUB-COMMITTEE of the Aberdeen Branch of the Children's Nutrition Council has made a survey in response to a suggestion of the Director of Education for Aberdeen that local authorities, having the power to provide free meals out of public funds for necessitous school children, would find it very useful if some standard by which to judge 'necessity' in every particular case could be made available. It may be of interest to mention that such a standard was approved by the Board of Education and has been in use for the last three years in Chester. It was designed by the present writer for the Chester Education Committee, and its purpose was to determine appropriate maintenance allowances to be paid in respect of children awarded special places in secondary schools, taking into account the size of the family income. Each case was previously dealt with on its merits, and some gave rise to a good deal of discussion and consequent waste of time. Now, all are settled automatically by reference to an objective scale of income needs. There is no doubt that such scales will in due course be adopted generally throughout Britain. They are obviously more scientific than the prevailing methods of assessment, which mostly take into account only the available income per head and aim at keeping grants below an agreed limit selected on no very rational basis.

Assuming payment of rent and rates or taxes has been made out of income, what is the minimal net balance needed for the adequate maintenance of any given family? That, in essence, is the question to which those who made the Aberdeen survey sought an answer. It will be noted that it is virtually the same question as that Sir William Beveridge had to consider in framing the allowances, under his Plan for Social Security, to be paid to families in want due to the cessation of earnings or some other cause. It will therefore be of interest to compare his estimated figures with those proposed as a result of the Aber. deen inquiry.

Those who are at work on such problems should always bear in mind also the results of the analysis of a random sample of nearly 9,000 weekly budgets of households, living in industrial areas, collected by the Ministry of Labour in 1937-38. These budgets give authoritative information about the actual expenditure of working-class families, and can be accepted as more widely representative than the figures which result from any purely local inquiry. They provide an invaluable check on estimates of the minimal necessary expenditure of low-income families in a particular area.

The Aberdeen Branch of the Children s Nutrition Council found that the cost of a suitable diet for a moderately active man in August 1942 was 8s. $9 d$. a week. This is one of the key figures used in the Aberdeen survey. To translate 'persons' into 'stand. ard' men, each person less than fourteen years of age was given a man value of $0 \cdot 65$, while each person of fourteen years and more was reckoned as one, irrespective of sex. This is a second key figure in the inquiry. Nearly two thirds of the thirty families investigated spent 45-60 per cent of their available income on food (available, that is, after deducting rent and taxes). Accordingly, 55 per cent was taken as

* A Budgetary and Dietary /Survey of Low-Income Families, Aberdeen, August 1942. By a Sub-Committee of the Aberdeen Branch of the Children's Nutrition Council. Pp. 28. (Aberdeen University Press, 1943.) the ratio which expenditure on food normally bears to available income in families with small incomes and two or more children to support. This is a third key figure in the inquiry, for it is thence assumed that the basic minimal income per man value per week should be taken as $\frac{100}{55}$ of $8 s .9 d .$, or $16 s$. , for this type of family.

In the Beveridge Report it is stated that it would have been possible, at 1938 prices, "to provide an adequate dietary, either on the scale laid down in the 1936 and 1938 Reports of the Technical Commission on Nutrition by the League of Nations or on the scale laid down in 1933 by the Committee on Nutrition of the British Medical Association, for a man and woman together at a cost of about $13 \mathrm{~s}$. a week". This, Sir William Beveridge suggested, could reasonably be subdivided: $7 s$. for a man and $6 s$. for a woman. The corresponding average figure for a child, on the League of Nations dietary, he put at 5s. 11d. Allowing for the change in prices since 1938, the Beveridge food standard becomes about $8 s$. for a man, 6s. 10d. for a woman and $6 s$. $9 d$. for a child in August 1942 ; whereas the Aberdeen standard at that date is $8 s .9 d$. for a man or woman and $5 s .9 d$. for a child. When the two standards are applied to a family of husband, wife and three children, the Beveridge standard provides 35s. 1d. and the Aberdeen standard 34s. 9 . for the purchase of food. Compensation is thus made for the rather high allowances given in Aberdeen to each parent-when compared with the League of Nations standard as interpreted in the Beveridge Report-by the rather low allowances given to the children.

According to the Ministry of Labour budgets, 46 per cent of the average net expenditure per household (after subtracting the average amount spent on rent and rates) was accounted for by food in 1937-38. But these families included many in good as well as in poor circumstances, so that the 55 per cent taken as the corresponding proportion in Aberdeen for low-income families does not seem unreason. able. For the present purpose the average budget expenditure may also be taken as a rough guide to the minimal cost of household and personal sundries. If, at a guess, one third of the actual average budget expenditure, say, $8 s .6 d$., is accepted as a reasonable minimum allowance for a family with three children, and account is taken of the rise in prices by August 1942, we have the following estimate deduced from the average budget family figure : $12 s$. I0d., as compared with 13s. 6d., the Aberdeen allowance. For clothing, and fuel and light, the Aberdeen scale for the same family may be more fittingly compared with the standards used by Sir William Beveridge, although these are really based also on the budget figures. Allowing for price changes, the figures are 9s. and 6s., respectively (Aberdeen), and 10s. $7 d$. and 6s. 4d. (Beveridge).

Several important points are stressed by the authors in the account they give of this survey. There is no space left to comment upon them here, but the hope may be expressed that the report will be widely studied by representatives of local authorities who are closely concerned with the problems raised, and that they will be encouraged thereby to adopt suitable scales for their own areas. Such scales should, of course, be revised periodically to allow for price changes and, possibly, generally improving standards of living. This is done once a year in Chester. 